Research Article

\title{
An outpatient department based observational study to review the pattern of utilization of proton pump inhibitors for their co-relation with the indications in a tertiary care centre
}

\author{
Jayant Kumar Kairi*, M. Fadil Salmani
}

Department of Pharmacology, Army College of Medical Sciences, Delhi Cantt, New Delhi-110010, India

Received: 01 July 2016 Accepted: 05 August 2016

*Correspondence to: Dr. Jayant Kumar Kairi, Email: jayantkairi@gmail.com

Copyright: (C) the author(s), publisher and licensee Medip Academy. This is an openaccess article distributed under the terms of the Creative Commons Attribution NonCommercial License, which permits unrestricted noncommercial use, distribution, and reproduction in any medium, provided the original work is properly cited.

\begin{abstract}
Background: Proton pump inhibitors (PPIs) are one of the commonest drugs prescribed for a variety of indications. They are considered remarkably safe and prescribed liberally. However, on long term administration, they can cause a number of adverse effects. In a tertiary care hospital, where the patient numbers are large and many attending super speciality centre, a number of patients were observed to receive PPIs for approved and unapproved indications. It was therefore considered prudent to study the prescribed PPIs for a co-relation with their indications or otherwise so as to formulate corrective interventions.

Methods: The observational study was conducted in the dispensary of a tertiary care centre. The prescriptions of the patients were the study material. Prescriptions for a full week were taken in for consideration. A total of 4142 prescriptions were studied. All aspects related to PPIs were noted and analysed. Additionally, a note on prescribed calcium supplements, vitamins and antioxidants was made.

Results: Of all the prescriptions studied by us, $33 \%$ had PPIs in them. Omeprazole was the commonest PPI followed by pantoprazole. Almost half the patients prescribed PPIs, the duration of administration was over 30 days. $78 \%$ patients prescribed PPIs also had some or the other non-steroidal antiinflammatory drug (NSAID) in their prescription. Over one fourth of the total patients also received calcium supplements, vitamins or anti-oxidants.

Conclusions: Proton pump inhibitors are very popular drugs and are being prescribed for approved and unapproved indications in the hope of providing relief to the patients. They are being advised quite liberally and more so if any NSAID has been co-prescribed. Even for prescriptions lasting for less than 5 days, PPIs have been included in the presumption to prevent gastritis due to NSAIDs. This practice is contrary to guidelines and also exposes the patients to avoidable adverse drug reactions.
\end{abstract}

Keywords: PPIs, NSAID, Omeprazole, Overuse

\section{INTRODUCTION}

Proton pump inhibitors along with $\mathrm{H} 2$ receptor antagonists are fourth highest prescribed drug groups after hypolipidemics, analgesics and antidepressants amongst all ages in United States and also are widely prescribed world over. ${ }^{1}$ The PPIs are considered to be remarkably safe and this impression has led to very liberal prescribing practices for this group of acid suppressants. The overwhelming capability of the PPIs to cause acid suppression, both basal as well as stimulated makes them the drug with highest efficacy for acid suppression. By the end of three days of administration, the acid output is reduced by $>70 \%$. $^{2}$ All the common members of PPI group of medicines- omeprazole pantoprazole rabeprazole and lansoprazole are comparable in their efficacy as acid suppressants and hence are considered to be interchangeable, especially in the hospital settings. The minor differences that exist are due to pharmacokinetics and methods of administration. ${ }^{3}$ 
Even though, PPIs are considered to be very safe drugs, they are not completely devoid of problems or potential problems. Some well-known adverse effects of long term administration of PPIs are rebound hypergastrinemia, greater incidence of community acquired pneumonias, vitamin B12 deficiency and enhanced risk of hip fractures especially older women. There are significant risks of drug interactions with a number of drug groups, notable amongst which are ketoconazole, ampicillin, iron, digoxin, theophylline, warfarin, diazepam, atazanavir and phenytoin. ${ }^{4}$

In a tertiary care government hospital like ours, more than half the patients are treated in sub-speciality centres and there is significant amount of polypharmacy. Sometimes there is no rationalisation of the medicines prescribed from different OPDs. Under these circumstances, we felt it imperative to take up this study to evaluate the prescription of PPIs and try to find out a co-relation with the indications for which they have been prescribed. It is felt that based on the outcome of this study some interventions could be planned to reduce the irrational prescribing of these simple, yet expensive group of medicines with potential harm on long term use.

\section{METHODS}

This study was conducted in the dispensary of a tertiary care government hospital. The materials for analysis were the prescriptions presented at the dispensary from various OPDs for one week (Monday to Saturday). The demographic characteristics were noted with respect to age and gender and whether PPI was prescribed or not was noted. Various characteristics related to the PPI were also noted. If the prescription contained PPI, then it was checked for the presence of non-steroidal antiinflammatory drugs [NSAID(s)]. Additionally, a note was made if the prescription contained any haematinic, calcium supplement or anti-oxidant. The data extracted was tabulated using Microsoft Excel and analysed using the same software.

\section{RESULTS}

A total of 4142 prescriptions were studied and analysed. It was found that 1371 patients had PPIs prescribed in their prescription. Table 1 represents the demographic details of our patients. Majority of our patients are females and belong to the age group between 30-70 years. Amongst the PPIs the patients received omeprazole the most, followed by pantoprazole. Rabeprazole, the most expensive of the lot was received by about $14 \%$ of all patients prescribed PPIs. The details of PPIs in prescriptions and their correlation with NSAIDS are represented in Table 2 and Figure 1 It is noteworthy that almost half the patients received PPIs for durations more than 30 days. It is most probable that these patients receive PPIs on a long term basis as many of them are seen to be suffering from chronic pain conditions, mostly joint related disabilities. Interestingly, next most commonly prescribed duration was for less than 5 days for minor painful conditions. An overwhelming majority (78\%) of patients with PPIs in their prescription had some or the other NSAID also prescribed.

Table 1: Patient demographics.

\begin{tabular}{|lll|}
\hline Parameter & \multicolumn{1}{l}{ Range } & No. $(\%)$ \\
\hline & & \\
\hline \multirow{3}{*}{ Age $(\mathbf{n}=\mathbf{4 1 4 2})$} & $(31-50$ Years $)$ & $207(5)$ \\
\cline { 2 - 3 } & (51-70 Years) & $1947(47)$ \\
\cline { 2 - 3 } & (>70 Years) & $1000(24)$ \\
\hline $\begin{array}{l}\text { Gender } \\
(\mathbf{n}=\mathbf{4 1 4 2})\end{array}$ & Males & $988(24)$ \\
\cline { 2 - 3 } & Females & $1823(44)$ \\
\hline
\end{tabular}

Table 2: PPI related information.

\begin{tabular}{|c|c|c|}
\hline Parameter & Description & No. $(\%)$ \\
\hline \multirow{3}{*}{$\begin{array}{l}\text { Number of drugs in } \\
\text { the prescription } \\
(n=4142)\end{array}$} & 2 or less & $870(21)$ \\
\hline & $3-5$ & $3024(73)$ \\
\hline & 6 or more & $248(5.9)$ \\
\hline \multirow{5}{*}{$\begin{array}{l}\text { Name of PPI } \\
\text { prescribed } \\
(n=1371)\end{array}$} & Omeprazole & $471(34)$ \\
\hline & Pantoprazole & $453(33)$ \\
\hline & Rabeprazole & $198(14.4)$ \\
\hline & Esomeprazole & $179(13)$ \\
\hline & Lansoprazole & $70(5.1)$ \\
\hline \multirow{4}{*}{$\begin{array}{l}\text { Duration of PPI } \\
\text { administration } \\
(n=1371)\end{array}$} & $<5$ days & $322(25.3)$ \\
\hline & 5-10 days & $298(21.7)$ \\
\hline & 11-30 days & $90(6.5)$ \\
\hline & $>30$ days & $661(48.2)$ \\
\hline
\end{tabular}

Table 3: PPI prescribed patients with diagnoses.

\begin{tabular}{|llll|}
\hline Parameter & $\begin{array}{l}\text { Whether } \\
\text { NSAIDs co- } \\
\text { prescribed }\end{array}$ & Niagnosis & No. (\%) \\
\hline & & $\begin{array}{l}\text { Arthritides } \\
\text { (OA/RA/ } \\
\text { Chronic joint } \\
\text { condition) }\end{array}$ & $376(34)$ \\
& & $\begin{array}{l}\text { Short term } \\
\text { injury/ } \\
\text { nonspecific } \\
\text { pains }\end{array}$ & $218(20)$ \\
PPI in & $\begin{array}{l}\text { Yes } \\
\text { prescription } \\
(n=1371)\end{array}$ & $\begin{array}{l}\text { Cardiovascular } \\
\text { preventive } \\
\text { (aspirin) }\end{array}$ & $279(25.5)$ \\
& & $\begin{array}{l}\text { Without } \\
\text { diagnosis }\end{array}$ & $219(20)$ \\
\cline { 2 - 4 } & $\begin{array}{l}\text { No } \\
(\mathrm{n}=279)\end{array}$ & $\begin{array}{l}\text { Confirmed } \\
\text { PUD }\end{array}$ & $159(57)$ \\
\cline { 2 - 4 } & $22 \%$ & $\begin{array}{l}\text { Dyspeptic } \\
\text { symptoms }\end{array}$ & $120(43)$ \\
\hline
\end{tabular}

It is revealed that reason for the NSAID was either due to CVS conditions mostly anti-platelet actions or as an analgesic anti-inflammatory drug for various arthritis's 
mostly rheumatoid arthritis or osteoarthritis. For the patients who had PPI in their prescription without an accompanying NSAID, they had either confirmed or presumptive acid peptic disease. The details are summarised in Table 3. Most of the patients received medicines between 3 to 5 in number. There was a trend to prescribe medicines that are popularly believed to increase well-being as given in Table 4. Calcium supplements, haematinics, and antioxidants topped the list of well-being promoting drugs. Almost one fourth of all patients received at least one of these three drugs. A pictorial depiction is presented at Figure 2.

Table 4: Other co-administered supplements.

\begin{tabular}{|c|c|c|}
\hline Drug & $\begin{array}{l}\text { Whether } \\
\text { supplement given }\end{array}$ & No. (\%) \\
\hline \multirow{2}{*}{$\begin{array}{l}\text { Haematinic } \\
(\mathrm{n}=4142)\end{array}$} & Yes & 1397 (33.7) \\
\hline & No & $2745(66.3)$ \\
\hline \multirow{2}{*}{$\begin{array}{l}\text { Calcium/vitamin } \\
\text { D supplements } \\
(\mathrm{n}=4142)\end{array}$} & Yes & $1528(37)$ \\
\hline & No & $2614(63)$ \\
\hline \multirow{2}{*}{$\begin{array}{l}\text { Anti-oxidants } \\
(\mathrm{n}=4142)\end{array}$} & Yes & $907(22)$ \\
\hline & No & $3235(78)$ \\
\hline
\end{tabular}

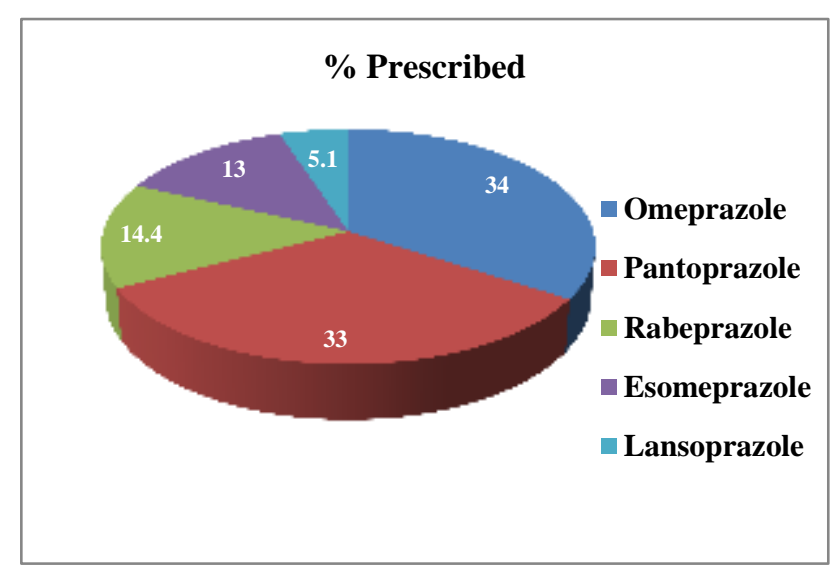

Figure 1: PPIs prescribed by type.

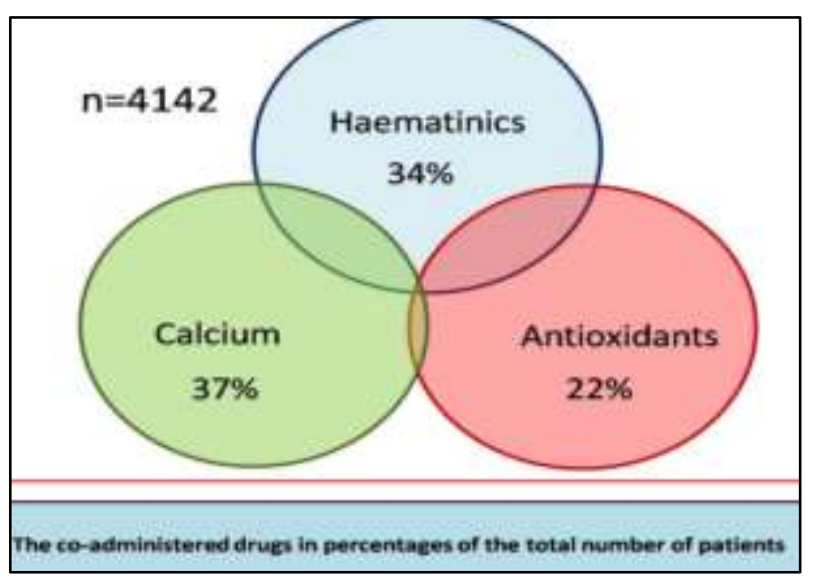

Figure 2: Other co-administered drugs.

\section{DISCUSSION}

PPIs are the most potent and popular drugs for gastric acid suppression. They have well defined indications and are approved for gastroesophageal reflux disease, peptic ulcer disease (includes H. Pylori associated, NSAIDs associated, and prevention of re-bleeding), non-ulcer dyspepsia, prevention of stress related mucosal bleeding and prevention of gastrinoma and other hyper secretory conditions. ${ }^{5}$ However due to their purported safety, over prescription of PPIs is a well-recognised phenomenon world over. ${ }^{6}$ A large segment of Indian population receives its healthcare from government hospitals where treatment is provided free of charge. There is a crunch of resources and money available to procure medication is limited. In such circumstances it is imperative that only rational prescribing occurs and wastage due to unnecessary prescribing is prevented. ${ }^{7}$

It is quite evident from our study that the PPI use by the patients is comparable to those in many other studies done abroad. It is observed that all patients who have a valid indication for receiving PPIs have been prescribed the medicine. Keeping in line with the expectations, in our study too it is noted that the patients who are on long term NSAID therapy either due to joint related pain or due to anti-platelet action with aspirin, were provided the protection of PPIs. Various rheumatology treatment guidelines providing associations worldwide advocate coprescribing of PPIs as protective therapy against NSAID associated ulcers. [8] There is no doubt about this practice in case of patients who are at increased risk. The increased risk is defined as elderly age, prior history of acid peptic disease, use of glucocorticoids or anticoagulants, high dosages of NSAIDs and disability due to other ailments. ${ }^{9}$

However, to include a PPI in every case of NSAID prescription may not be a rational decision. Evidence for the same is either lacking or very weak. The guidelines in case of patients on aspirin for anti-platelet actions are equivocal with respect to PPI protection. In such circumstances only the patients who are considered to be at a high risk of erosive gastritis or bleeding due to aspirin or NSAIDs should be given the PPI protection. ${ }^{10}$ In our study, it is observed that a very high percent (20\%) of patients who received short term NSAIDs for injury or pain also got PPI along with, on a presumption that it will prevent the NSAID induced gastritis. It is a welldocumented fact that for periods up to 3 days in low doses (usually for analgesic antipyretic action), the chances of gastritis due to NSAIDs is not more than that with paracetamol. ${ }^{11}$ All patients receiving NSAIDs for short duration and those on aspirin for anti-platelet effects could have been advised to have the medicine after meals and avoid consuming it empty stomach. This is a standard guidance contained in the patient information leaflets of US FDA and UK Medicines and Healthcare Products Regulatory Agency (MHRA). ${ }^{12,13}$ This simple measure would reduce the chances of NSAID induced gastritis and 
the PPI administration was avoidable. The patient could have been advised to consult in case of any complaints subsequent to the treatment and the same could have been addressed later on. The inclusion of a PPI everywhere a NSAID has been written in the prescription is irrational and needs intervention in the form of physician as well as patient education. More importantly, in our study it is observed that almost $20 \%$ of patients who were prescribed PPIs and NSAIDs did not have a diagnosis written on the prescription. This, furthermore, confirms the suspicion that the decision to include the PPI was not taken after due consideration. Nearly $11.5 \%$ patients prescribed PPIs were confirmed cases of PUD or GERD. A total of 120 (roughly 8\%) patients of those 1371 who got PPIs, received it for presumptive APD due to dyspeptic symptoms. The literature does not support such a use of PPIs and there is negligible evidence to support this practice. In fact there is no evidence to support event the use of $\mathrm{H} 2$ receptor antagonists also for such indication. ${ }^{14}$

On a closer look at our study data, it is observed that $48 \%$ of patients who received PPIs, they did so for periods more than 30 days. This is alarming for the reason that these patients are on chronic medications for their diseases. Whether it is arthritis's, cardio vascular conditions or PUD, these patients seek review rarely. Keeping in mind the chronic nature of these conditions, it is not very abnormal also. By experience, such patients have observed that unless there are fresh symptoms, the physicians are inclined to continue the medications. Therefore, these patients continue to take the medications in the prescription for a long time, sometime beyond a few years. This is dangerous, considering the fact that PPI use over long term are well documented to cause harm in various ways. ${ }^{15,16}$ Prescribing PPIs in hospitalized patients for prevention of stress ulcers is a standard practice. It is possible that PPI was included in the discharge advice irrationally or by overlook and got continued with their long term treatment. $48 \%$ of total patients studied by us belong to the elderly group of more than 50 years of age. Elderly patients have the highest risk of potential adverse effects due to PPIs, considering the possibility of polypharmacy and chronic nature of their conditions. Polypharmacy and elderly age group are well known risk factors for drug interactions and adverse drug reactions. $^{17,18}$

The maximum number of patients in our study received between 3-5 medicines in their prescriptions which is similar to other studies performed to study drug utilization. Additionally, $37 \%$ patients of the total studied received calcium supplements. Some of the patients could need these calcium supplements due to valid indications. However, for most patients with normal diet and absorptive systems, routine calcium supplementation is not only unnecessary but also potentially harmful. ${ }^{19}$ Likewise, $33 \%$ patients were prescribed haematinics and $22 \%$ received anti-oxidants as part of their treatment. Antioxidants are not proven to be of survival benefit for any ailment till date. ${ }^{20}$ Hence it can be inferred that the inclusion of antioxidants is for providing a placebo cum feel good factor. Inclusion of medicines in prescriptions that are not actually indicated or are of dubious benefit should be avoided. They increase the chances of harm due to adverse drug reactions and also the cost of therapy.

To summarise, it has been observed in our study that there is a definite trend towards irrational PPI prescribing, especially when an NSAID also has been co-prescribed for short duration. This practice is justified only for patients at enhanced risk of NSAID induced harm. There is also a trend to prescribe calcium supplements, haematinics and antioxidants which may not be indicated for all the patients. Interventions are needed to educate the physicians as well as patients regarding the perils of irrational prescribing.

\section{Funding: No funding sources \\ Conflict of interest: None declared \\ Ethical approval: The study was approved by the Institutional Ethics Committee}

\section{REFERENCES}

1. National Center for Health Statistics. Health, United States, 2015: With Special Feature on Racial and Ethnic Health Disparities. Hyattsville, MD. Table 80; 2016:274.

2. Mejia A, Kraft WK. Acid peptic diseases: pharmacological approach to treatment. Expert review of clinical pharmacology. 2009;2(3):295-314.

3. McQuaid KR. Drugs used in the treatment of gastrointestinal diseases. In: Katzung BG, eds. Basic and Clinical Pharmacology. $13^{\text {th }}$ ed. New York, NY: McGraw-Hill; 2015:1052-83.

4. Wedemeyer RS, Blume H. Pharmacokinetic drug interaction profiles of proton pump inhibitors: an update. Drug Safety. 2014;37(4):201-11.

5. Wallace JL, Sharkey KA. Pharmacotherapy of Gastric acidity, peptic ulcers, and gastroesophageal reflux disease. In Brunton L, Chabner B, Knollman B, eds. Goodman and Gilman's The Pharmacological Basis of Therapeutics. $12^{\text {th }}$ ed. New York, NY: McGraw-Hill; 2011:1309-1322.

6. Heidelbaugh JJ, Kim AH, Walker PC. Overutilization of proton pump inhibitors: what the clinicians need to know. Ther Adv Gastroenterology. 2012;5(4):219-32.

7. Heidelbaugh JJ, Inadomi JM. Magnitude and economic impact of inappropriate use of stress ulcer prophylaxis in non-intensive care unit hospitalized patients. Am J Gastroenterol. 2006;101:2200-05.

8. Sturkenboom MC, Burke TA, Dieleman JP, Tangelder MJ, Lee F, Goldstein JL. Underutilization of preventive strategies in patients receiving NSAIDs. Rheumatology (Oxford). 2003;42(S3):2331.

9. Laine L. Approaches to non-steroidal antiinflammatory drug use in the high risk patient. Gastroenterology. 2001;120:594-606. 
10. Shim YK, Kim N. NSAID and aspirin-induced peptic ulcer disease. Korean J Gastroenterol. 2016;67(6):300-12.

11. Bjarnason I. Ibuprofen and gastrointestinal safety: a dose-duration-dependent phenomenon. J R Soc Med. 2007;100(S48):11-4.

12. USFDA patient information advice hosted on US National Library of Medicine. Available at https:/www.nlm.nih.gov/medlineplus/druginfo/meds/ a682159.html. Accessed 26 June 2016.

13. UK Medicines and Healthcare Products Regulatory Agency (MHRA) approved Patient Information Leaflet. Available at https://www.medicines.org.uk/emc/PIL.26628.latest. pdf. Accessed 26 June 2016.

14. Valle JD. Peptic ulcer disease and related disorders. In Kasper DL, Fauci AS, Hauser SL, Longo DL, Jameson JL, Loscalzo J, eds. Harrison's Principles of Internal Medicine. $19^{\text {th }}$ ed. New York, NY: McGrawHill; 2015:1911-32.

15. Reimer C, Sondergaard B, Hilsted L, Bytzer P. Proton-pump inhibitor therapy induces acid-related symptoms in healthy volunteers after withdrawal of therapy. Gastroenterology. 2009;137:80-7.
16. Gray SL, LaCroix AZ, Larson L, Robbins J, Cauley JA, Manson JE, et al. Proton pump inhibitor use, hip fracture, and change in bone mineral density in postmenopausal women. Arch Int Med. 2010;170:765-71.

17. Haider SI, Johnell K, Thorslund M, Fastbom J. Trends in polypharmacy and potential drug-drug interactions across educational groups in elderly patients in Sweden for the period 1992 - 2002. International Journal of Clinical Pharmacology and Therapeutics. 2007;45(12):643-53.

18. Juurlink DN, Mamdani M, Kopp A, Laupacis A, Redelmeier DA. Drug-drug interactions among elderly patients hospitalized for drug toxicity. JAMA. 2003;289(13):1652-58.

19. Bolland MJ, Avenell A, Baron JA, Grey A, MacLennan GS, Gamble GD, et al. Effect of calcium supplements on risk of myocardial infarction and cardiovascular events: meta-analysis. BMJ. 2010;341:c3691.

20. Bessell E, Jose MD, McKercher C. Associations of fish oil and vitamin B and E supplementation with cardiovascular outcomes and mortality in people receiving haemodialysis: a review. BMC Nephrol. 2015;16:143.

Cite this article as: Kairi JK, Salmani MF. An outpatient department based observational study to review the pattern of utilization of proton pump inhibitors for their co-relation with the indications in a tertiary care centre. Int J Basic Clin Pharmacol 2016;5:2001-5. 